tương tự nghiên cứu của Pham Hồng Đức [7] và Marco [5]. Như vậy kích thước ổ dị dạng vỡ theo nhiều nghiên cứu có liên quan đến hiện tượng chảy máu não. Ổ dị dạng có kích thước nhỏ và trung bình có nguy cơ võ cao hơn ổ có kích thước lớn.

Động mạch não giữa tham gia cấp máu cho ổ dị dạng chiếm $52,78 \%$ các trường hợp, động mạch não trước là $25 \%$, động mạch não sau là 33,33\%. Ngoài ra một số ổ dị dạng còn được cấp máu bởi các nhánh động mạch tiểu não. Kết quả này phù hợp với nhận định của Pham Hồng Đức [7] cho rằng khu vực động mạch nã̇o giữa là khu vực hay gặp nhất vì động mạch não giữa là một động mạch lớn và là nguồn cung cấp máu cho phần lớn bán cầu não của hệ tuần hoàn trước.

Trong nghiên cứu của chúng tôi phần lớn các ổ dị dạng võ có từ hai cuống mạch nuôi trở lên $(63,89 \%)$, các ổ dị dang vỡ thường là những ổ có một tĩnh mạch dẩn lưu duy nhất $(72,2 \%)$, điều này cũng tương tự với các nghiên cứu của nhiều tác giả khác.

\section{KẾT LUÂNN}

Độ tuổi hay gặp nhất của các bệnh nhân AVM võ là từ trên 40 tuổi chiếm tỷ lệ 63,9\%; tuổi trung bình $43 \pm 14,7$. Bệnh gặp ở cả hai giới với tỷ lệ nam/nữ là 1,27/1. Chảy máu do vỡ AVM là chảy máu thùy chiếm $85,72 \%$. Ổ dị dạng võ thường là ổ có kích thước nhỏ $<3 \mathrm{~cm}$, có một tĩnh mạch dẫn lưu duy nhất.

\section{TÀI LIÊU THAM KHẢO}

1. Friedlander RM. Arteriovenous malfor- mations of the brain. N Engl J Med 2007; 356:2704-12.

2. Cognard C, Spelle L., and Pierot L. (2004), Pial arteriovenous malformations in: Intracranial vascular malformations and aneurysm, Springer. 39-92.

3. Shaligram S.S., Winkler E., Cooke D. và công sứ. (2019). Risk factors for hemorrhage of brain arteriovenous malformation. CNS Neurosci Ther, 25(10), 1085-1095.

4. Phan Văn Đức, Lê Văn Thính, Hoàng Văn Thuân (2018), siêu âm Doppler xuyên so và hình ảnh chụp mạch máu não của dị dạng thông đông-tĩnh mach nã̃o.

5. Marco A.Stefani, Phillip J.Porter, et al (2002), Large and deep brain arteriovenous malformation are associated with risk of future hemorrhage, Stroke, 3. 1220.

6. Deruty $R$, et al (1985), Les malformations Arterio-veineuses Cerebrales, Neurochir, 31. 21-29

7. Pham Hồng Đức, Pham Minh Thông, Lê Văn Thính (2010), Các yễu tố cấu trúc mạch liên quan đên biểu hiện xuất huyết của dị dạng động tînh mach não, Tạp chí $Y$ học thực hành $(705)$ số 2, 52-55.

\title{
TÌM HIỂU MộT Số YẾU TỐ LIÊN QUAN ĐẾN KẾT QUẢ KIỂM SOÁT HUYẾT ÁP Ở BÊ̂NH NHÂN TĂNG HUYẾT ÁP ĐIỀU TRI NGOẠI TRÚ TẠI BÊ̂NH VIÊ̂N ĐA KHOA HUYỆN LỤC NGẠN
}

\section{TÓM TẮT}

Mục tiêu: Tìm hiểu một số yếu tố liên quan đến kết quả kiểm soát huyết áp ở bệnh nhân tăng huyết áp điêu trị ngoại trú tại Bệnh viện Đa khoa huyện Lục Ngạn năm 2020. Đối tượng và phương pháp nghiên cứu: Nghiên cứu mồ tả cắt ngang được thực hiện từ tháng 7/2020 đến tháng 10/2021 trền 500 bệnh nhân tăng huyết áp được điều trị ngoại trú tại Bệnh viện Đa khoa huyện Lục Ngạn. Kết quả: Tỉ lệ đạt huyết áp mục tiêu là $25,6 \%$, nữ cao hơn nam với tỉ lê $31,6 \%$ và $18,6 \%$, tuân thủ thuốc đat $76 \%$. Có mối liên quan giữa giới tính $(p=0,001)$, tiền sử gia đình bị tăng huyết áp $(p=0,022)$, bệnh đái tháo đường

\footnotetext{
${ }^{1}$ Trường Đại học Y Hà Nội,

${ }^{2}$ Viện Tim mach Viêt Nam-Bênh viên Bach Mai

Chịu trách nhiệm chính: Đồng Thị Ngọc Lâm

Email: khileocay47@gmail.com

Ngày nhận bài: 9.9.2021

Ngày phản biên khoa hoc: 25.10.2021

Ngày duyệt bài: 10.11.2021
}

Đồng Thị Ngọc Lâm 1 , Nguyễn Thị Bạch Yến ${ }^{2}$

kèm theo $(p=0,025)$, thời gian bị tăng huyết áp $(p=0,033$ và 0,028$)$, số nhóm thuốc huyết áp và tổng số thuốc sử dụng hàng ngày với kết quả kiểm soát huyết áp $(p<0,001)$. Kết luận: Có mối liên quan giữa giới tính, tiền sử gia đình bị tăng huyết áp, bệnh đái tháo đướng kèm theo, thời gian bị tăng huyết áp, số nhóm thuốc huyết áp và số thuốc sử dụng hàng ngày với kết quả kiểm soát huyết áp.

Tư khóa: các yếu tố liên quan đến kiểm soát huyết áp.

\section{SUMMARY}

\section{TO STUDY SOME FACTORS RELATED TO THE RESULTS OF BLOOD PRESSURE CONTROL IN HYPERTENSIVE PATIENTS TREATED AS OUTPATIENTS AT LUC NGAN DISTRICT GENERAL HOSPITAL}

Objectives: To study some factors related to the results of blood pressure control in hypertensive patients treated as outpatients at Luc Ngan District General Hospital in 2020. Subjects and methods: A 
cross-sectional descriptive study was carried out from July 2020 to October 2021 on 500 hypertensive patients treated as outpatients at Luc Ngan District General Hospital. Results: The rate of reaching the target blood pressure was $25.6 \%$, female was higher than male with the rate of $31.6 \%$ and $18.6 \%$, drug adherence reached $76 \%$. There was an association between sex $(p=0.001)$, family history of hypertension $(p=0.022)$, concomitant diabetes mellitus $(p=0.025)$, duration of hypertension $(p=0.033$ and 0.028$)$, number of groups of blood pressure drugs and total number of drugs used daily with blood pressure control results $(p<0.001)$. Conclusion: There is a relationship between gender, family history of hypertension, concomitant diabetes, duration of hypertension, number of blood pressure drug classes and daily use of drugs with control results. blood pressure control.

Keywords: Factors related to blood pressure control.

\section{I. ĐẶT VẤN ĐỀ}

Tăng huyết áp là một bệnh mạn tính có tốc độ gia tăng rất nhanh và đang là một vấn đề lớn đối với sức khỏe cộng đồng trên toàn thế giới. Tăng huyết áp là nguyên nhân hàng đầu của các bệnh tim mạch và tử vong do tim mạch. Kiểm soát tốt huyết áp mục là điều quan trọng nhất giúp giảm các gánh nặng bệnh tật do tăng huyết áp gây nên. Tuy nhiên việc kiểm soát huyết áp ở các bệnh nhân tăng huyết áp còn rất kém, tỉ lệ kiểm soát huyết áp mục tiêu ở các nước phát triển và đang phát triển vẫn còn thấp do có rất nhiều yếu tố ảnh hưởng đến việc kiểm soát huyết áp. Do đó nhằm tăng hiệu quả kiểm soát huyết áo mục tiêu chúng tôi đã tiến hành nghiên cứu đề tài "Tim hiểu một số yếu tố liên quan đên kêt quả kiểm soát huyêt áp ở bệnh nhân tăng huyết áp điều trị ngoại trú tại Bệnh viện Đa khoa huyện Luc Ngạn ".

\section{II. ĐỐI TƯỢNG VÀ PHƯƠNG PHÁP NGHIÊN CỨU}

1.Đối tượng nghiên cứu. Người bệnh được chẩn đoán THA và được điều trị ngoại trú tại bệnh viên đa khoa huyện Lục Ngạn tỉnh Bắc Giang năm 2020

\section{> Tiêu chuẩn lựa chơn:}

- Người bệnh được chẩn đoán THA ${ }^{8}$.

- Tuổi $\geq 18$ tuổi.

- Có sổ theo dõi điều trị ngoại trú.

- Đã được theo dõi và điều trị $\geq 3$ tháng.
- Đồng ý tham gia nghiên cứu.

\section{> Tiêu chuân loại trứ:}

- Người bệnh được chẩn đoán THA nhưng không có bệnh án ngoại trú

- Người bệnh THA nhưng không đi khám đều

- Đang có bệnh nội khoa nặng:

- Các tình trạng sốc, suy hô hẩp, nhiễm trùng nặng

- Ung thư giai đoạn cuối

- Suy thận mạn có chạy thận nhân tạo

- Nhồi máu cớ tim cấp

- Tai biến mạch máu não giai đoạn cấp

- Đái tháo đường nặng có biến chứng như tăng áp lực thẩm thấu, nhiềm toan, nhiễm trùng - Những bệnh nhân THA bị khiếm thị, khiếm thính, rối loạn tâm thần, thiểu năng trí tuệ

- Không đồng ý tham gia nghiên cứu

2.Thời gian và địa điểm nghiên cứu. Nghiên cứu được tiến hành từ tháng 7 năm 2019 đến tháng 10 năm 2021 tại Bệnh viện Đa khoa huyện Lục Ngạn tỉnh Bắc Giang.

\section{Phương pháp nghiên cứu}

> Thiêt kế nghiên cứu: Nghiên cứu mô tả cắt ngang.

Sử dụng phương pháp chọn mẫu ngẫu nhiên thuận tiện. Bất kỳ người bệnh nào đến khám, nếu đáp ứng đủ tiêu chuẩn lựa chọn và không vi phạm tiêu chuẩn loại trừ sẽ được chọn vào nghiên cứu cho đến khi đủ 500 người.

\section{> Công cư thu thập và xứ lý số liệu}

Sử dụng bộ câu hỏi nghiên cứu phù hợp dựa trên bộ câu hỏi Morisky và KAP, tham khảo những thông tin liên quan từ sổ điều trị ngoại trú của bệnh nhân.

Sử dụng phần mềm Epidata để nhập dữ liệu. Xử lí và phân tích số liệu bằng phần mềm Stata.

Sử dụng tần số, tî̉ lệ phần trăm và phương pháp hồi quy logistic để tìm mối tương quan.

\section{KẾT QUẢ NGHIÊN CỨU}

500 bệnh nhân trong nghiên cứu có độ tuổi trung bình là $57 \pm 9$, trẻ nhất là 19 và cao tuổi nhất là 88.

Nam nhiêu hơn nữ, với nam là 231 người chiếm 46,2\% và nữ có 269 người chiếm 53,8\%.

Tỉ lệ đạt huyết áp mục tiêu chung, huyết áp tâm thu mục tiêu và huyết áp tâm trương mục tiêu lần lượt là 25,6\%-27\%-71\%.

Bảng 3.1 Môi liên quan giữa đặc điểm chung với kiểm soát huyêt áp

\begin{tabular}{|c|c|c|c|c|c|}
\hline \multirow{2}{*}{ Yếu tố } & \multicolumn{2}{|c|}{ HAMT } & \multirow{2}{*}{ OR } & \multirow{2}{*}{ KTC95\% } & P \\
\cline { 2 - 3 } Nhóm tuối: $<40$ & Đạt & Không đạt & & - & Tham chiếu \\
\hline $40-64$ & 4 & 11 & 1 & - & 0,895 \\
\hline$>=65$ & 105 & 267 & 1,08 & $0,34-3,47$ & $0,16-1,93$ \\
\hline Giới tính: $\quad$ Nam & 19 & 94 & 0,55 & 0,356 \\
\hline
\end{tabular}


VIETNAM MEDICAL JOURNAL N¹ - DECEMBER - 2021

\begin{tabular}{|c|c|c|c|c|c|}
\hline Nữ & 85 & 184 & 2,02 & $1,33-3,07$ & 0,001 \\
\hline Dân tộc: Kinh & 76 & 231 & 1 & - & Tham chiếu \\
\hline Khác & 52 & 141 & 1,12 & $0,74-1,69$ & 0,585 \\
\hline Trình độ học vấn & \multicolumn{5}{|l|}{} \\
\hline Không biết chữ & 3 & 13 & 1 & - & Tham chiếu \\
\hline Tiểu học & 70 & 206 & 1,47 & $0,41-5,32$ & 0,555 \\
\hline THCS & 36 & 116 & 1,34 & $0,36-4,98$ & 0,658 \\
\hline THPT & 18 & 34 & 2,29 & $0,58-9,11$ & 0,238 \\
\hline CĐ, ĐH và sau ĐH & 1 & 3 & 1,44 & $0,11-19,21$ & 0,781 \\
\hline
\end{tabular}

Nhận xét: Nhóm tuối từ 40-64 tuối đạt HAMT cao nhất.

Giới nữ có tỉ lệ đạt HAMT cao hơn giới nam tỉ lệ 31,6\%-18,6\%.

Nhóm có trình độ hoc vấn là THPT có tỉ lê đạt HAMT cao nhất

Có mối liên quan giữa giới tính và việc kiểm soát huyết áp. Với $O R=2,02 ; p=0,001$.

Bảng 3.2 Môi liến quan giữa tiên sử bệnh với kiểm soát huyết áp

\begin{tabular}{|c|c|c|c|c|c|}
\hline \multirow{2}{*}{ Yếu tố } & \multirow{2}{*}{\multicolumn{2}{|c|}{ HAMT }} & \\
\hline & & & OR & KTC95\% & $\mathbf{P}$ \\
\hline \multicolumn{6}{|c|}{ Tiên sử gia đình bị THA } \\
\hline Có & 59 & 129 & 1 & - & Tham chiếu \\
\hline Không & 69 & 243 & 0,62 & $0,41-0,93$ & 0,022 \\
\hline \multicolumn{6}{|c|}{ Tiền sử hút thuốc lá } \\
\hline Không hút & 103 & 277 & 0,58 & - & Tham chiếu \\
\hline Đã bỏ thuốc lá & 15 & 49 & 0,82 & $0,44-1,53$ & 0,539 \\
\hline Đang hút & 10 & 46 & 0,58 & $0,28-1,2$ & 0,144 \\
\hline \multicolumn{6}{|l|}{ Uống rượu } \\
\hline Có & 29 & 118 & 1 & - & Tham chiếu \\
\hline Không & 99 & 254 & 1,58 & $0,99-2,53$ & 0,053 \\
\hline \multicolumn{6}{|c|}{ Đái tháo đường } \\
\hline Có & 19 & 91 & 1 & - & Tham chiếu \\
\hline Không & 109 & 281 & 1,86 & $1,08-3,19$ & 0,025 \\
\hline \multicolumn{6}{|l|}{ BMI } \\
\hline Không thừa cân & 66 & 164 & 1 & - & Tham chiếu \\
\hline Thừa cân & 32 & 100 & 0,79 & $0.49-1,29$ & 0,359 \\
\hline Béo phì & 30 & 108 & 0,69 & $0,42-1,13$ & 0,142 \\
\hline \multicolumn{6}{|c|}{ Số năm bị THA } \\
\hline$<1$ năm & 35 & 67 & 1 & - & Tham chiếu \\
\hline 1-5 năm & 69 & 225 & 0,59 & $0,36-0,96$ & 0,033 \\
\hline 5-10 năm & 20 & 53 & 0,72 & $0,37-1,39$ & 0,332 \\
\hline$\geq 10$ năm & 4 & 27 & 0,28 & $0,09-0,87$ & 0,028 \\
\hline \multicolumn{6}{|c|}{$\begin{array}{l}\text { Nhân xét: Những bênh nhân có tiền sử gia } \\
\text { đình bị tăng huyết áp có tỉ lệ kiểm soát huyết áp } \\
\text { cao hơn nhóm có tiên sữ gia đỉnh bị tăng huyết áp. } \\
\text { Những bệnh nhân không hút thuốc lá, không } \\
\text { uông rượu bia, không bị đái tháo đường có tỉ lệ đạt } \\
\text { huyết áp mục tiêu cao hơn so với nhóm còn lại. } \\
\text { Những bệnh nhân bị tăng huyết áp dưới } 1\end{array}$} \\
\hline \multicolumn{6}{|c|}{ Bảng 3.3 Môí liên quan giữa đặc điểm về thuốc sử dụng và kiểm soát huyêt áp } \\
\hline \multirow{2}{*}{ Yếu tố } & & HAMT & OR & KTC95\% & $\mathbf{P}$ \\
\hline & Đạt & Không đạt & . OK & & \\
\hline \multicolumn{6}{|c|}{ Số nhóm thuốc HA } \\
\hline 1 nhóm & 102 & 76 & 1 & & Tham chiếu \\
\hline 2 nhóm & 26 & 220 & 0,06 & $0,04-0,11$ & 0,000 \\
\hline 3 nhóm & 0 & 69 & 0,03 & $0,0004-0,02$ & 0,000 \\
\hline 4 nhóm & 0 & 7 & - & - & - \\
\hline
\end{tabular}




\begin{tabular}{|c|c|c|c|c|c|}
\hline \multicolumn{7}{|c|}{ Tống số thuốc sử dụng môi ngày } \\
\hline$<3$ thuốc & 110 & 229 & 1 & - & Tham chiếu \\
\hline$\geq 3$ thuốc & 18 & 143 & 0,262 & $0,15-0,45$ & 0,000 \\
\hline
\end{tabular}

Nhận xét: Những bệnh nhân sử dụng 1 loại thuốc huyết áp đạt tị lệ kiếm soát huyết áp cao nhất là $57,3 \%$. Bệnh nhân dùng ít hơn 3 thuốc mỗi ngày sẽ có tỉ lệ kiểm soát huyết áp cao hơn.

Có mối liển quan giữa số nhóm thuốc huyết áp và tổng số thuốc sử dụng mổi ngày đến kiểm soát huyết áp với $p<0,001$.

Bảng 3.4 Mối liên quan giữa kiến thức, thực hành, tuân thủ thuốc với kiểm soát huyêt áp

\begin{tabular}{|c|c|c|c|c|c|}
\hline Yếu tố & & AMT & OR & KTC 95\% & $\mathbf{p}$ \\
\hline Kiến thức: Tốt & Đạt & Không đạt & & & $\mathbf{P}$ \\
\hline Chưa tốt & $\frac{85}{43}$ & $\frac{247}{125}$ & 1 & $0,65-1,53$ & 0,999 \\
\hline Thực hành: Tốt & 104 & 281 & 140 & $085-232$ & 0187 \\
\hline Chưa tốt & 24 & 91 & 1,40 & & \\
\hline $\begin{array}{c}\text { Tuân thủ thuốc: Tốt } \\
\text { Chưa tốt }\end{array}$ & $\frac{97}{31}$ & $\frac{283}{89}$ & 0,98 & $0,61-1,57$ & 0,946 \\
\hline
\end{tabular}

Nhận xét: Nhóm bệnh nhân có kiến thức tốt, thực hành tốt và tuân thủ thuốc tốt có tỉ lệ đạt huyết áp mục tiêu tương tự các nhóm còn lại.

Không có mối liên quan giữa kiến thức, thực hành và tuân thủ thuốc của bệnh nhân với kiểm soát huyết áp.

\section{BÀN LUẬN}

Trong nghiên cứu của chúng tôi tỉ lệ kiểm soát huyết áp là $25,6 \%$. Kết quả này cao hơn so với nghiên cứu của tác giả Phạm Thái Sơnvà Huỳnh Văn Minh ${ }^{9}$. Nhưng kết quả này thấp hơn so với kết quả nghiên cứu của tác giả Bent $M$. Egan, Nguyễn Thu Hằng, Nguyễn Thị Thắm, Teshome ${ }^{3,4}$. Trong nghiên cứu của chúng tôi thấy có mối tương quan giữa kiểm soát huyết áp với các yếu tố về giới tính, tiền sử gia đình bị tăng huyết áp, tiền sử bị đái tháo đường, thời gian bị tăng huyết áp, số nhóm thuốc huyết áp và tổng số thuốc sử dụng hàng ngày với $\mathrm{p}<0,05$. Trong khi các yếu tố về tuổi, trình độ học vấn, dân tộc, tình trạng thừa cân béo phì, tiền sử hút thuốc lá và rượu bia và tuân thủ thuốc không có mối liên quan với kết quả kiểm soát huyết áp.

Kết quả này có sự tương đồng và khác biệt với các nghiên cứu của các tác giả trong và ngoài nước. Như theo nghiên cứu của tác giả Phạm Thái Sơn cho thấy tỉ lệ kiểm soát huyết áp ở nữ giới cao nam giới với $p<0,001$.

Nghiên cứu của tác giả Muleta cũng cho thây có 5 yếu tố liên quan đến kết quả kiểm soát huyết áp gồm tuổi cao, giới tính nữ, thời gian bị tăng huyết áp trên 5 năm, tuân thủ điều trị và đường huyết không kiểm soát với $p<0,05$. Tác giả Dedefo nghiên cứu về các yếu tố liên quan đến kiểm soát huyết áp và kết quả cho thây tuổi cao, thời gian bị tăng huyết áp trên 5 năm, không tuân thủ điều trị, hút thuốc lá và đường huyết không kiểm soát là những yếu tố dự báo độc lập về tình trạng huyết áp không kiểm soát được với $p<0,05$. Nghiên cứu của tác giả Fekadu cũng cho thấy giới nam, mù chữ, thời gian bi tăng huyết áp trên 10 năm, không tuân thủ và lười vận động có liên quan đến việc kém kiểm soát huyết áp, trong khi tuổi cao lại là yếu tố liên quan đến kiểm soát huyết áp tốt hơn, $p<0,05$.

Theo tác giả Animut thì yếu tố hoạt động thể chất, thời gian bị tăng huyết áp trên 2 năm, tuân thủ thuốc là những yếu tố liên quan tích cực đối với kiểm soát huyết áp tốt, còn chế độ ăn mặn, tình trạng thừa cân béo phì là yếu tố làm tăng tî lệ kém kiểm soát huyết áp với $p<0,05$.

Nghiên cứu của tác giả Yang cho Kết quả cho thấy những người cao tuổi, sống ở nông thôn và ngoại thành, trình độ học vấn thấp, tiền sử gia đình bị tăng huyết áp, hút thuốc lá, ăn quá nhiêu muối, lười vận động, thừa cân, béo phì và đái tháo đường có liên quan đến tăng huyết áp không kiểm soát với $p<0,05$.

Kết quả nghiên cứu của tác giả Iloh cho thây kiểm soát HA có liên quan đáng kể với tuân thủ thuốc, thời gian dùng thuốc hạ áp $\geq 3$ năm, và dùng $\geq$ một dạng thuốc hạ áp với $p<0,05$.

\section{KẾT LUÂNN}

Tỉ lệ đạt huyết áp mục tiêu là $25,6 \%$. Nữ giới kiểm soát tốt hơn nam giới lần lượt là $31,6 \%$ và $18,6 \%$.

Tỉ lệ tuân thủ thuốc chung là 76\%.

Tỉ lệ phối hợp thuốc điêu trị đạt $64,4 \%$ trong đó chủ yếu là phối hợp 2 thuốc với tỉ lệ 49,2\%.

Có mối liên quan giữa giới nữ, tiên sử gia đình bị tăng huyết áp, bệnh đái tháo đường kèm theo, thời gian bị tăng huyết áp, số nhóm thuốc huyết áp và tổng số thuốc sử dụng mỗi ngày với kiểm soát huyết áp mục tiêu $(p<0,05)$.

\section{TÀI LIỆU THAM KHẢO}


1. Egan BM, Kjeldsen SE, Grassi G, Esler M, Mancia G. The global burden of hypertension exceeds 1.4 billion people: should a systolic blood pressure target below 130 become the universal standard? 2019;37(6):1148-1153. doi:10.1097/hjh.0000000000002021

2. Huỳnh Văn Minh, Nguyển lân Việt. Blood pressure screening during the May Measurement Month 2017 programme in Vietnam-South-East Asia and Australasia. Eur Heart J Suppl. Apr 2019;21(Suppl doi:10.1093/eurheartj/suz076

3. Redon J, Tellez-Plaza M, Orozco-Beltran D, et al. Impact of hypertension on mortality and cardiovascular disease burden in patients with cardiovascular risk factors from a general practice setting: the ESCARVAL-risk study. J Hypertens. Jun 2016;34(6):1075-83. doi: $10.1097 / \mathrm{HJH} .0000000000000930$

4. Ettehad D, Emdin CA, Kiran A, et al. Blood pressure lowering for prevention of cardiovascular disease and death: a systematic review and metaanalysis. Lancet. Mar 5 2016;387(10022):957-967. doi:10.1016/S0140-6736(15)01225-8

5. Legido-Quigley $H$, Camacho Lopez PA, Balabanova D, et al. Patients' knowledge, attitudes, behaviour and health care experiences on the prevention, detection, management and control of hypertension in Colombia: a qualitative study. PLoS One. 2015;10(4):e0122112. doi:10.1371/journal.pone.0122112

6. Nguyễn Lân Việt. Phòng chống tăng huyết ápGiảm gánh nặng bênh tật. Dự án phòng, chống bênh tim mạch- Chương trình mục tiêu Quốc gia về y tế. 2011;

7. Tổng Hôi $\mathbf{Y}$ hoc Viêt Nam, Bô $\mathbf{Y}$ Tế. Hôi nghi Khoa hơc toàn quốc lần thứ VỉI-2017, chủ đề phòng chống các bênh không lây nhiếm. Bô Y Tế. Accessed 12/9, 2021. https://moh.gov.vn/tin-lienquan/-/asset_publisher/vjYyM709aWnX/ content/hoi-nghi-khoa-hoc-toan-quoc-lan-thu-vii2017-chu-e-phong-chong-cac-benh-khong-laynhiem?inheritRedirect $=$ false

8. Hội Tim mạch học Quốc gia Việt Nam. Khuyến cáo về chẩn đoán và điểu trị tăng huyết áp Accessed 15/8, 2021. http://vnha.org.vn/data/ Khuyen-Cao-THA-2018.pdf

9. Pham Thái Sơn, Nguyễn Ngọ Quang Nguyễn Lân Việt, et al. Prevalence, awareness, treatment and control of hypertension in Vietnamresults from a national survey. J Hum Hypertens. Apr 2012;26(4):268-80. doi:10.1038/jhh.2011.18

\title{
NGHIÊN CỨU HOÀN THIỆN YOGA TRI LIỆU VIẸT NAM ĐỂ PHỤC HỒI CHỨC NĂNG CHO BẸNH NHÂN DI CHỨNG TAI BIẾN MACH MÁU NÃO TẠI BỆNH VIÊ̂N ĐA KHOA THÀNH PHỐ HÀ TĨNH
}

\author{
Trần Nguyên Phú ${ }^{1}$, Võ Thị Trang ${ }^{1}$, Hoàng Ngọc Hà ${ }^{1}$, \\ Đặng Hùng ${ }^{2}$, Lê Thị Huyền Trang ${ }^{1}$, Lê Thị Thanh Thủy ${ }^{1}$, \\ Ngô Thị Thúy Diễn', Nguyễn Thị Mỹ Trang1, \\ Trần Thị Ngọc ${ }^{1}$, Nguyễn Sử Minh Ngọc'
}

\section{TÓM TẮT}

Nghiên cứu thử nghiệm lâm sàng ngẫu nhiên có đối chứng trên 2 nhóm người bênh nhằm đánh giá kết quả phương pháp Yoga trị liệu Việt Nam phục hồi chức năng (PHCN) người bệnh tai biến mạch máu não (TBMMN). 80 người bệnh di chứng TBMMN đã được điều trị giai đoạn cấp ổn định, tuổi từ $40-75$ tuổi, không phân biệt giới tính, nghề nghiệp, tình nguyên tham gia nghiên cứu. 40 người bệnh nhóm nghiên cứu phuc hồi chức năng bằng phương pháp Yoga trị liêu Việt Nam, nhóm đối chứng điêu trị PHCN thông thường. Kết quả được so sánh sau 90 ngày điêu trị cho thấy $75 \%$ người bệnh ở nhóm can thiệp giảm 2 mức độ liệt trở lên, tỳ lệ này ở nhóm đối chứng là 42,5\%

\footnotetext{
${ }^{1}$ Bệnh viện Đa khoa thành phố Hà Tïnh

2 Học viện Yoga Việt Nam

Chiu trách nhiệm chính: Trần Nguyên Phú

Email: Trannguyenphu@gmail.com

Ngày nhận bài: 13.9.2021

Ngày phản biện khoa học: 2.11 .2021

Ngày duyệt bài: 15.11.2021
}

$(p<0,05)$. Ngoài ra huyết áp, sức khỏe tinh thần, mức độ độc lập trong sinh hoạt hằng ngày, nguy cơ té ngã cải thiên tốt hơn có ý nghĩa thống kê so với trước khi điều trị và nhóm đối chứng.

Tư khóa: tai biến mạch máu não, yoga, yoga trị liệu Việt Nam, phục hồi chức năng

\section{SUMMARY \\ YOGA THERAPY VIETNAM PROCESS ON REHABILITATING SEQUENCES OF CEREBROVASCULAR ACCIDENT PATIENTS}

Study on a randomized controlled clinical trial on 2 groups of patients to evaluate the results of Vietnamese yoga therapy in rehabilitation of patients with cerebrovascular accident. 80 patients with cerebral vascular accident sequelae were treated in stable acute phase, aged 40-75 years old, regardless of gender, occupation, and volunteered to participate in the study. 40 patients in the study group had their rehabilitation by the method of Vietnamese yoga therapy, and the control group had received conventional rehabilitation treatment. Compared results after 90 days of treatment showed that $75 \%$ of 